\title{
Impact of the COVID19 pandemic on the implementation of Health Information Technologies (HIT): a case study in Maternity Hospital of Lubango-Angola
}

Tomas Hambili Paulo Sanjuluca ( $\sim$ tomashambili@yahoo.com.br)

Faculty of Medicine of Mandume Ya Ndemufayo University ,Huila-Angola

\section{Ricardo Cruz-Correia}

Faculty of Medicine of the University of Porto

Anabela Antunes Almeida

Faculty of Social and Human Sciences, University of Beira Interior

\section{Research Article}

Keywords: COVID19, Implementation, Health Information Technologies, Computerized Health information systems, Angola

Posted Date: August 18th, 2021

DOI: https://doi.org/10.21203/rs.3.rs-786387/v1

License: @ (i) This work is licensed under a Creative Commons Attribution 4.0 International License. Read Full License 


\section{Abstract \\ Background}

COVID19 pandemic has shown the importance of data to manage health crises. Therefore, countries that were more mature regarding using Information Systems (IS) were better prepared to respond to their population needs. Unfortunately, in Angola, such Health Information Systems (HIS) maturity is very low, so new Health Information Technology (HIT) projects must change this scenario.

\section{Objective}

Describe the impact of COVID19 on a new health information technology project called "ObsCare Lubango" to collect essential data on deliveries and births at the Maternity Hospital in Lubango-Angola.

\section{Methods}

Retrieve data from the notes, communication events of the project management. Also, the collected data regarding obstetrics (pregnancies and childbirth) was from Jan 2019 to Apr 2021 (14 months before COVID19 and 14 months after the beginning of COVID19). The data analyzed were collected from the utilization audit trail that stores the sessions and clicks in the application logs. These logs are then presented in aggregated and anonymized form in a web interface.

\section{Results}

The start of COVID19 in Maternity halted the evolution of the health information project implementation. At the beginning of 2020 , the usage of ObsCare Lubango was growing steadily $(5.9 \%, 7.5 \%, 9.4 \%$ in the first three months), but rapidly dropped to $0 \%$ in the following months after the first of COVID arrived in late March.

\section{Conclusion}

COVID19 had a significant impact on the evolution of ObsCare Lubango and heavily impacted the quality of the data collected in the paper. COVID19 will probably increase the digital divide in health care between nations.

\section{Background}

COVID-19 Pandemic in Angola was confirmed on the 21st of March 2020, forcing the Angolan government to declare a state of emergency in Angola on the 27th of March 2020 under the Presidential Decree No. 81/20 of the 25th of March. After that, state public calamity, decreed by the President of Republic through Presidential Decree No. 142/20, of the 25th of May, came into force, with new public and private services for the prevention of Covid-19, which prevails until this moment. Since the first case of COVID-19 was reported, Angolans had to consent to enormous sacrifices. They were subject to significant restrictions in their lives, resulting from the government's measures[1, 2].

COVID-19 pandemic has shown the importance of data to manage health crises. Therefore, countries that were more mature regarding using Information Systems (IS) were better prepared to respond to their population needs[3].

Unfortunately, in Angola, such Health Information Systems (HIS) maturity is very low, so new projects must change this scenario[4]. 
At the beginning of the Covid-19 pandemic, the World Health Organization (WHO) included Angola among the least prepared countries to face the new coronavirus [5-7]. Before COVID-19 in general, the HIS in Angola needed urgent reinforcement and improvement measures to function efficiently because the existing had significant weaknesses that hindered monitoring implementation and evaluating results, assessing the quality of services, and monitoring professionals' performance according to international parameters and standards[8].

Predictably, it may be much more dramatic, the impact of the pandemic in addition to South Asia, in other countries, such as Africans with fewer resources where hospitals are close to collapse, with a lack of beds and oxygen, the number of changes increases significantly, and vaccines lack. For example, statistical health data show that malaria is one of the leading health problems in Angola. There is evidence that deaths from malaria in a quarter are higher than deaths from COVID-19 over a year[9].

The use of Computerized Health Information Systems (CHIS) influences the quality of health service provision. Initiatives for implementing these electronic systems in health have been taking place internationally, improving health services, quality, and efficiency in inpatient care and scientific research. Countries with reputations of leaders in the reform of health services, creation and adoption of CHIS, such as England, Denmark, Switzerland, United States, Canada, Australia, New Zealand, Portugal, are examples of some countries that make considerable investments in the implementation of these systems[10].

Being an innovation for many developing countries, implementing successful new information technology (IT) applications has lessened skepticism about these approaches, overcoming uncertainties and driving their implementation. Nevertheless, the real concerns and many resistance remain, but investments to support the implementation of $\mathrm{CHIS}$ in developing countries must be balanced with resources available for other health needs[11-13].

Data reliability was an issue discussed in almost all countries at the beginning of the pandemic. The COVID-19 pandemic forced health managers to reorganize their work routines. HIS must be flexible, prepared for the changes within health services, with or without pandemic crises. This pandemic came to demand from managers and health professionals the use of information technologies. However, because of all the shortcomings affecting HIS of developing countries, in this phase of the COVID-19 pandemic, we cannot rule out the hypothesis that there is an increase in underreporting or even a lack of local clinical, epidemiological records. A situation that should be less impactful if health institutions had to use CHIS[14].

Unfortunately, many health professionals and hospital support staff at this Maternity hospital of Lubango (the place of implement a project) tested positive for COVID-19. Therefore, prevention measures had to be made in this health institution, like closing some services, suspension of all administrative activities, or the technicians being forced to be in confinement because of the COVID risk.

In this phase of the pandemic, technological solutions reduce the number of people in healthcare spaces and provide quick and easy access to services and patient information. The pandemic of COVID-19 is a milestone in the technological revolution in the health sector. It imposed the need for new strategies and adaptation of services to act in the face of social distance such as connected initiatives, service communication, innovations of health communications and telemedicine, performance in assistance, communication, and training of health professionals[15].

Information and communication technology (ICT) has and will continue to play an essential role in managing the data to improve patient care in daily clinical services[16]. Moreover, together with engineering strategies, ICT provides an excellent opportunity to enhance the design of hospital care $[17,18]$.

Despite its importance, most of the information systems (IS) in hospitals in Angola are not computerized (traditional paper system). Therefore, the user does not have a unique identification, i.e., every time they go to the health services, they are always considered a new patient. The management of clinical information is essential because it can only achieve accurate 
decisions and better health indicators with the construction and use of data. Without an effective health information system, it isn't easy to achieve proper hospital management, adequate research, or even better problem-based health training $[19,20]$.

Several authors suggest that hospital managers should make much more effort to develop a strategy and policy on HIT deployment so that the hospital improves information management and decision-making processes and the quality of health services[21].

Based on the problems of the information system at the level of hospitals in Angola, the Faculty of Health Sciences at the University of Beira Inferior, in the context of a Ph.D. in Biomedicine, approved a research project on technologies and information systems in health and hospital management, which aimed to transfer technological innovations to solve the problems of the information system in an academic hospital, mother-child, in the sanitary region of southern Angola (Lubango city).

The technological innovation process at the maternity hospital in Lubango-Angola denominated "ObsCare-Lubango" consists of adopting a computerized hospital information system. Before implementing this project, we performed a preevaluation to identify the barriers and opportunities[22]. Naturally, we did not foresee the pandemic state and its implications. Because of this unpredictable situation with the emergence of COVID-19, we are obliged to assess the execution of the project. To guide our study, we asked the following research question: What was the impact of this unforeseen COVID-19 on implementing a new computerized hospital information system in Angola?

The present study aims to describe the impact of COVID-19 in implementing the new computerized hospital information system project "ObsCare Lubango" at the maternity in Huila -Angola hospital.

\section{Methods}

\section{Design Study}

The design study is based on qualitative research principles. It is a case study that measures the impact of COVID-19 in implementing a computerized hospital information system" ObsCare-Lubango" in a single hospital[23]. In the first phase, the "ObsCare-Lubango" project is implemented in this hospital, in admission services medical archives and statistics.

\section{Data collection}

The first phase was the collection of data regarding the hospital context and the Obscare-Lubango project. This is relevant to understand better what happened when the pandemic state got to Angola and the impact of such a project.

The second phase was to measure the impact of COVID-19 in the implementation of the project. We selected as study variables: the number of deliveries performed, the number of records introduced in the ObsCare-Lubango application, the time of use of the same application, births, and maternal deaths converted before and during a pandemic.

The data analyzed were collected from the utilization audit trail that stores the sessions and clicks in the application logs. These logs are then presented in aggregated and anonymized form in a web interface.

\section{Application design and features}

This technological solution is called "ObsCare-Lubango," which is fundamentally an electronic clinical record system, which fully supports the gynecological and obstetric practice. Whose design or development of the prototype based on an adaptation of an application developed by a team of researchers from the Center for Research in Technology and Health Information Systems of the Faculty of Medicine of the University of Porto, called ObsCare, which is industrial property of Virtual Care - Systems for life (VC), a spin-off of the University of Porto. 
This application is essentially an electronic clinical record system, which provides complete support for the gynecological and obstetric practice. The reason for our decision to adopt this application for the Maternity hospital of Lubango, which includes care in these areas. The results of the effectiveness in the collection and analysis of obstetric information demonstrated in eleven institutions of the regional health administration of northern Portugal that already use it, such as the University Hospital of Porto "São João," which has been using the same application for more than twenty years ago reinforced our choice to adopt this application.

ObsCare-Lubango has specifically as characteristics of insertion/survey and analysis of obstetric data, namely: Hospitalizations (Admission and Discharges) and births (Birth data, Births, Abortion Records, Instrumented deliveries, suction cups, and forceps and cesarean sections), and generate reports of 142 maternal and neonatal health indicators of this institution, through the menus of characteristics of this technological application, it is possible to assess the degree of use of the same ObsCare-Lubango application.

\section{Data analysis}

This study analyses data from the hospital's information system, 28 months divided into two periods: before COVID-19 (January 2019 to February 2020) and after the emergence of COVID-19 in Angola (March 2020 to April 2021). Totalling twenty-eight months from January 2019 to April 2021 (14 months before COVID-19 and 14 months after COVID-19 started).

The data collected aimed to obtain information, thinking about the impact that COVID-19 had on the project in execution, of implementing an electronic hospital information system, which is to justify the need to readjust the tasks and schedule of the project. Therefore, using Excel as a data treatment tool, the collected data were subject to interpretation and descriptive analysis using graphs and frequency tables to describe the variables under study.

\section{Results}

\section{Healthcare context}

The hospital has a capacity of 180 beds, with the main strengths of gynecology, obstetrics, and neonatal services, which, in addition to assistance, support tasks in three domains: teaching, research, and school. ObsCare-Lubango project has been implemented since the 1st of November 2019 at the admissions Service's medical archives and statistics of the maternity hospital. It is a public hospital and has existed for more than twenty years. This project is the first of its kind (electronic clinical information management) at this institution. The collected data were from January to April 2021.

\section{Implementation Obscare-Lubango project}

Specifically, to have a perception of the use of the "ObsCare-Lubango" application and the impact that COVID-19 had on this project in execution, it took as a starting point to consider two dates: the 1st of November 2019, data indicative of the beginning of the phase of implementation of the project in the AAMSS, of the maternity hospital and the 20th of March, 2020, is the date of notification of the first case of COVID-19 in Angola. Therefore, we are considering a total of eighteen months to evaluate the "ObsCare-Lubango" application (November 2019 to April 2021). Thus, the period before COVID-19 in Angola is four months (November 2019 to February 2020), and the period after COVID-19 in Angola is 14 months (March 2020 to April 2021).

This period in the analysis compared the variables clinical processes recorded in ObsCare-Lubango and the days of use of the same application in each period. Results in Graphic 1 show that the use of the application in each month, from the observation period in the implementation phase (November 2019 to April 2021), has always been less than 15 days. During this period under analysis, 63 days were used, out of 547 days, for disclosure for the use of the application. Assuming that they should use the application every day, during the eighteen months, they used the ObsCare-Lubango application in the order of $11.5 \%$ of the total days completed for use.

\section{Impact of COVID in Obscare-Lubango project}


We can observe (Graph 1) that in the period from November 2019 to March 2020 (the period before COVID-19), there was an upward trend, both for the number of records entered in ObsCare- Lubango as well as the days of use of the application. Checks for a sudden drop from April to October 2020. Whereas in a normal situation of a data insertion process of deliveries, we should assume that the number of deliveries performed must correspond to the number of clinical records entering the application in an electronic hospital information system.

The findings in Table 1 offers us, in a more illustrative way, information to evaluate the use of the ObsCare-Lubango application before and during this phase of the COVID-19 pandemic, they show that in the comparison between the variable number of performed deliveries and the information of medical records introduced, in the ObsCare-Lubango., the percentage of variation is low (1.3\%). This means that out of 16,673 clinical records of deliveries performed during the observation period of the implementation phase (November 2019 to April 2021), entered only 351 records into ObsCare-Lubango, which implies that did not enter $98.7 \%$ of clinical records of deliveries performed into ObsCare-Lubango. Ideally, the number of clinical processes of deliveries performed should equal the number of records entered in ObsCare-Lubango. 
Table 1

Evaluation of the use of the ObsCare-Lubango application, observing the number of clinical records inserted in the application until April 2021

\begin{tabular}{|c|c|c|c|c|c|c|c|c|c|}
\hline Period & Months & Year & $\begin{array}{l}\text { Performed } \\
\text { Deliveries }\end{array}$ & $\begin{array}{l}\text { Clinical } \\
\text { Records } \\
\text { Introduced } \\
\text { in the } \\
\text { ObsCare- } \\
\text { Lubango. }\end{array}$ & $\begin{array}{l}\text { \%Variation } \\
\text { (Clinical } \\
\text { Records } \\
\text { Introduced } \\
\text { in the } \\
\text { ObsCare- } \\
\text { Lubango } \\
\text { /Deliveries } \\
\text { Performed) }\end{array}$ & $\begin{array}{l}\text { Days } \\
\text { of the } \\
\text { Month }\end{array}$ & $\begin{array}{l}\text { Days of } \\
\text { Using } \\
\text { the } \\
\text { ObsCare- } \\
\text { Lubango } \\
\mathrm{n}\end{array}$ & $\begin{array}{l}\% \\
\text { Variation } \\
\text { (Days of } \\
\text { Using of } \\
\text { the } \\
\text { ObsCare- } \\
\text { Lubango } \\
\text { /Days of } \\
\text { the } \\
\text { Month) }\end{array}$ & $\begin{array}{l}\text { Number } \\
\text { of } \\
\text { Maternal } \\
\text { Deaths }\end{array}$ \\
\hline \multirow{15}{*}{$\begin{array}{l}\text { Period } \\
\text { Before } \\
\text { COVID- } \\
19\end{array}$} & January & 2019 & 938 & & & & & & 7 \\
\hline & February & 2019 & 850 & & & & & & 9 \\
\hline & March & 2019 & 977 & & & & & & 6 \\
\hline & April & 2019 & 896 & & & & & & 5 \\
\hline & May & 2019 & 1043 & & & & & & 19 \\
\hline & June & 2019 & 987 & & & & & & 6 \\
\hline & July & 2019 & 1121 & & & & & & 15 \\
\hline & August & 2019 & 1071 & & & & & & 8 \\
\hline & September & 2019 & 1136 & & & & & & 9 \\
\hline & October & 2019 & 1104 & & & & & & 17 \\
\hline & November & 2019 & 1057 & 36 & 3,4 & 30 & 11 & 36,7 & 18 \\
\hline & December & 2019 & 1029 & 13 & 1,3 & 31 & 3 & 9,7 & 10 \\
\hline & January & 2020 & 1029 & 61 & 5,9 & 31 & 4 & 12,9 & 7 \\
\hline & February & 2020 & 1001 & 75 & 7,5 & 29 & 9 & 31,0 & 6 \\
\hline & Sub-total & & 14239 & 185 & 1,3 & 121 & 27 & 22,3 & 142 \\
\hline \multirow{11}{*}{$\begin{array}{l}\text { Pos } \\
\text { period } \\
\text { COVID- } \\
19\end{array}$} & March & 2020 & 1045 & 98 & 9,4 & 31 & 11 & 35,5 & 10 \\
\hline & April & 2020 & 876 & 0 & 0,0 & 30 & 0 & 0,0 & 8 \\
\hline & May & 2020 & 1006 & 5 & 0,5 & 31 & 1 & 3,2 & 5 \\
\hline & June & 2020 & 1091 & 0 & 0,0 & 30 & 0 & 0,0 & 6 \\
\hline & July & 2020 & 1016 & 0 & 0,0 & 31 & 0 & 0,0 & 6 \\
\hline & August & 2020 & 983 & 0 & 0,0 & 31 & 0 & 0,0 & 7 \\
\hline & September & 2020 & 961 & 0 & 0,0 & 30 & 0 & 0,0 & 9 \\
\hline & October & 2020 & 675 & 0 & 0,0 & 31 & 0 & 0,0 & 10 \\
\hline & November & 2020 & 634 & 30 & 4,7 & 30 & 6 & 20,0 & 13 \\
\hline & December & 2020 & 729 & 14 & 1,9 & 31 & 7 & 22,6 & 7 \\
\hline & January & 2021 & 779 & 8 & 1,0 & 31 & 4 & 12,9 & 7 \\
\hline
\end{tabular}

Source: Data from the Hospital Information System and from the ObsCare-Lubango application - April 2021 


\begin{tabular}{|c|c|c|c|c|c|c|c|c|c|}
\hline Period & Months & Year & $\begin{array}{l}\text { Performed } \\
\text { Deliveries }\end{array}$ & $\begin{array}{l}\text { Clinical } \\
\text { Records } \\
\text { Introduced } \\
\text { in the } \\
\text { ObsCare- } \\
\text { Lubango. }\end{array}$ & $\begin{array}{l}\text { \%Variation } \\
\text { (Clinical } \\
\text { Records } \\
\text { Introduced } \\
\text { in the } \\
\text { ObsCare- } \\
\text { Lubango } \\
\text { /Deliveries } \\
\text { Performed) }\end{array}$ & $\begin{array}{l}\text { Days } \\
\text { of the } \\
\text { Month }\end{array}$ & $\begin{array}{l}\text { Days of } \\
\text { Using } \\
\text { the } \\
\text { Obscare } \\
\text { Lubango } \\
n\end{array}$ & $\begin{array}{l}\text { \% } \\
\text { Variation } \\
\text { (Days of } \\
\text { Using of } \\
\text { the } \\
\text { ObsCare- } \\
\text { Lubango } \\
\text { /Days of } \\
\text { the } \\
\text { Month) }\end{array}$ & $\begin{array}{l}\text { Number } \\
\text { of } \\
\text { Maternal } \\
\text { Deaths }\end{array}$ \\
\hline & February & 2021 & 792 & 7 & 0,9 & 28 & 4 & 14,3 & 5 \\
\hline & March & 2021 & 981 & 4 & 0,4 & 31 & 3 & 9,7 & 10 \\
\hline & April & 2021 & 989 & 0 & 0,0 & 30 & 0 & 0,0 & 7 \\
\hline & Sub-total & & 12557 & 166 & 1,3 & 426 & 36 & 8,5 & 110 \\
\hline Total & & & 26796 & 351 & 1,3 & 547 & 63 & 11,5 & 252 \\
\hline
\end{tabular}

Considering November 2019, the indicative data to start the implementation of the ObsCare-Lubango project, until February 2020, as the period before the confirmation of COVID-19 in Angola, it is possible to verify (table 1) the values of the percentages of the variation $(3.4 ; 1.3 ; 5.9$ and 7.5$)$, during these four months, between the number of clinical records introduced in the application and the number of deliveries performed. This variation fluctuated within the range of $1.3 \%$ to $7.5 \%$.

Considering the period from March 2020 to April 2021 as the COVID-19 period. Comparing the percentage of variation between the number of clinical records introduced in the application and the number of parts performed in this period, the results in table 2 demonstrate that data for fourteen months of variations ranged from 0.0 to $9.4 \%$. There were months with deliveries but made no record in "ObsCare-Lubango."

The results visualization that three months after the implementation of the project (January February, and March 2020), the use of ObsCare Lubango was growing steadily $(5.9 \%, 7.5 \%, 9.4 \%)$ but quickly fell to $0 \%$ in the following months, after the arrival of the first case of COVID-19 in Angola, at the end of March.

There was a reduction in data-performed deliveries in institutional completed deliveries of $11.8 \%$ (from 14,239, before COVID-19, to 12,557 in a period during COVID-19). The same happened with maternal deaths, which decreased by $22.5 \%$ (from 142 in the period before COVID-19 to 110 during COVID-19).

\section{Discussion}

There was a worldwide trend towards health innovations driven by the pandemic ${ }^{38}$. Results of studies demonstrated that despite the consequences of this pandemic of COVID-19, there were many opportunities to implement digital technologies in health. Since the arrival of the COVID-19 pandemic, initiatives linked to technological innovations to digitize health and telemedicine services identify themselves at the level of several countries in the world[24].

Our results show a different reality. The results indicate that the implementation of ObsCare Lubango experienced two distinct moments: a first moment (January, February, and March 2020) of growth in the number of data insertions in the first three months after the implementation of the project, and a second moment (April 2020 to April 2021) of a drastic reduction, having months without inserting any data in the application. This second moment occurs after the notification of the first case of COVID-19 in Angola at the end of March. Here there is evidence that COVID-19 had a significant impact on the evolution of ObsCare Lubango. As a result, the execution of the project has a very worrying (negative) trajectory. It reached zero, which means there was a shallow frequency of using the application or even no use in several months. 
In a fully operational scenario, the should "ObsCare-Lubango" be used every day. However, the results (Graphic 1) show that they did not use it $80 \%$ of the days. These findings reinforce the idea that developing country governments, specifically health sector managers, cannot take advantage of information technologies in the health sector during emergency public health events, such as the Ebola crisis, cholera, typhoid, and now COVID-19[25].

Failure to use the "ObsCare Lubango" application in COVID-19 is an indicator of the vulnerability of the information system at the level of this hospital. Their health information systems (paper or electronic) should not stop working when pandemic crises arise. On the contrary, in these moments, they are even more necessary to provide information to support clinical and administrative procedures.

The results of (Table 1) show that there is a big difference between the number of clinical records introduced in the application concerning the number of existing clinical processes (number of parts performed), which means that few or almost none are introduced into the clinical system record of deliveries performed. These results raise many questions, will all births be accounted for. Have all the birth registration processes been completed and forwarded to the admission, filing, and medical statistics section? One of the causes of underreporting clinical or epidemiological data has been the lack of filling out the forms or forwarding the same processing areas.

Our study shows that COVID-19 and the impact on the evolution of ObsCare Lubango also had a substantial effect on the information flow and the quality of the data collected on paper in this hospital. Thus, the COVID-19 is likely to increase the digital divide in healthcare among nations, especially in developing countries[26, 27].

Our study shows that during COVID-19, there was a reduction in institutional deliveries and maternal deaths. Given these results, many questions arise: are we facing a situation of record registration or little demand for services? Should likely has been further reduced the impact of COVID-19 in the indicators, coverage of prenatal care services, utilization rate, limited access to health services, and a decrease in the number of institutional deliveries and births[28]. Other studies show that the direct and indirect consequences of pandemic COVID-19 on maternal health are interlinked. Its impact on reproductive and perinatal health is directly through infection itself and indirectly due to changes in health care, social policy, or social and economic circumstances[29].

Findings in studies emphasized that with the progress of the disease, the maternal mortality rate by COVID-19 increased. This rate may be even higher due to underreporting, difficulties in carrying out laboratory tests, and possible false-negative results depending on the health policies adopted in each region or country. In Angola, preventive measures against Covid19 , which in addition to being beneficial in reducing the emergence of new cases, had other repercussions that were not very positive for Angolans who had to consent to enormous sacrifices and limited access to health services[30, 31].

These results can assist in discussing the enhancement and contours to bottlenecks(unforeseen) in the implementation of Health Information Technology (HIT) projects. In addition, our study added reports a particular experience that cannot ignore for similar projects. Let us see that:

- During the pandemic of COVID-19, the implementation of new electronic information systems in hospitals not related to COVID-19 was very difficult. In addition, the lack of resources during COVID leads to a re-prioritization of projects, which may increase the digital gap between hospitals of developing and developed countries.

- The stress on providing healthcare during the COVID pandemic also decreases the time left to record clinical data. This effect will probably have a significant impact in the years to come, and it may be challenging to normalize healthcare.

\section{LIMITATIONS}

This study, taking into account the current pandemic situation and the reality of the study, was limited to analyzing the data from the "ObsCare Lubango" application on one hospital. 
There were also difficulties in having more information on what happened at the beginning of COVID regarding patient data collection.

\section{Conclusions}

COVID-19 had a significant impact on the evolution of the ObsCare Lubango project, but the quality of the data collected on paper was also strongly impacted. COVID-19 is likely to increase the digital divide in healthcare between nations.

Restriction measures, internal to the hospital, at the beginning of the Covid-19 pandemic, impacted the progress of implementing the "ObsCare-Lubango" project, having influenced the reduction in the time of use of the application. Having identified the impact caused by COVID-19, electronic, and the bottleneck factors (causes of failures and technical problems), there is a need to readjust the schedule in implementing a hospital information system in this health project institution of the project tasks.

Although the COVID-19 pandemic is a critical situation and not a choice, it is essential to understand that the experiences in this period can improve processes and flows in health information technology. Thus, it is crucial to generate reflection and encourage managers and leaders of health institutions, studies on the implementation of new information technologies, and seek to recognize them in the best way and assess their effects on the practices of patients' health systems.

\section{Declarations}

\section{Ethics approval and consent to participate}

Not applicable.

\section{Consent for publication}

Not applicable

\section{Availability of data and materials}

'Not applicable. But the data sets used or analyzed during the study are available in the manuscript tables.

\section{Competing interests}

The authors declare that they have no competing interests

\section{Funding}

This research received no specific grant from any funding agency in public, commercial or not-for-profit sectors.

\section{Authors' contributions}

Tomas Hambili (MSC) was primarily responsible for bibliographic research, manuscripts, data collection, and statistical analysis. Anabela Almeida (Ph.D.) and Ricardo Correia (Ph.D.) actively contributed to all parts of the article, including data interpretation, review, and text approval. In addition, all authors contributed to the elaboration of the data collection instrument.

\section{Acknowledgment}

We thank the General Direction and the professionals of the admission, archive, and medical statistics services of the Hospital Maternity do Lubango for the collaboration and provision of data for this study. Furthermore, to the staff of 
CINTESIS, for the maintenance and adjustments of ObsCare-Lubango.

\section{Abbreviations}

HIS-Health Information Systems

HIT-Health Information Technology

WHO -World Health Organization

CHIS -Computerized Health Information Systems 0

IT -Information technology ()

IS-Information Systems

VC -Virtual Care - Systems for life

\section{References}

[1] J. dos Santos Gomes, M. F. Neto, and M. M. G. Francisco, "impact of human and social sciences on combat to covid19 in brazil and angola," Revista Observatório, vol. 6, no. 2, pp. a2en-a2en, 2020.

[2] P. R. Cossengue, "An epistemological study on the impact of covid-19 on Angola' s business environment," RAC: Revista Angolana de Ciências, vol. 2, no. 2, pp. e020203-e020203, 2020.

[3] C.-O. Bagayoko, J.-C. Dufour, S. Camacho, O. Bouhaddou, and M. Fieschi, "Open source challenges for a hospital information system (HIS) in developing countries: a pilot project in Mali," BMC medical informatics and decision making, vol. 10, no. 1, pp. 1-13, 2010.

[4] A. J. M. Chimuco, "Sistema de informação da atenção primária em saúde: desenvolvimento e implantação do módulo do Programa de Agentes Comunitários de Saúde-Módulo PACS/SIAPS, no âmbito do subsistema de Saúde das Forças Armadas de Angola," 2014.

[5] R. E. G. Wadoum and A. Clarke, "How prepared is Africa to face COVID-19?" The Pan African Medical Journal, vol. 35, no. Suppl 2, 2020.

[6] S. A. Lone and A. Ahmad, "COVID-19 pandemic-an African perspective," Emerging microbes \& infections, vol. 9, no. 1, pp. $1300-1308,2020$.

[7] W. H. Organization, "Coronavirus disease 2019 (COVID-19): situation report, 73," 2020.

[8] C. Simões, "A gestão da pandemia SARS-CoV-2 em Angola," Cadernos Ibero-Americanos de Direito Sanitário, vol. 10, no. 2, pp. 277-285, 2021.

[9] A. Sumner, E. Ortiz-Juarez, and C. Hoy, Precarity and the pandemic: COVID-19 and poverty incidence, intensity, and severity in developing countries (no. 2020/77). WIDER Working Paper, 2020.

[10] D. A. Ludwick and J. Doucette, "Adopting electronic medical records in primary care: lessons learned from health information systems implementation experience in seven countries," International Journal of medical informatics, vol. 78, no. 1, pp. 22-31, 2009. 
[11] S. Krishna and G. Walsham, "Implementing public information systems in developing countries: Learning from a success story," Information Technology for Development, vol. 11, no. 2, pp. 123-140, 2005.

[12] S. Ajami and T. Bagheri-Tadi, "Barriers for adopting electronic health records (EHRs) by physicians," Acta Informatica Medica, vol. 21, no. 2, p. 129, 2013.

[13] S. Ajami and R. Arab-Chadegani, "Barriers to implement electronic health records (EHRs)," Materia socio-medica, vol. 25, no. 3, p. 213, 2013.

[14] J. Mantas, "The Importance of Health Informatics in Public Health During the COVID-19 Pandemic," in The Importance of Health Informatics in Public Health during a Pandemic: IOS Press, 2020, pp. 487-488.

[15] J. I. A. Kamal, "Implementation of electronic medical records in developing countries: Challenges and barriers," Development, vol. 7, p. 3, 2018.

[16] B. W. Pickering, J. M. Litell, V. Herasevich, and O. Gajic, "Clinical review: the hospital of the future-building intelligent environments to facilitate safe and effective acute care delivery," Critical care, vol. 16, no. 2, pp. 1-11, 2012.

[17] J.-L. Vincent, "Critical care-where have we been and where are we going?," Critical care, vol. 17, no. 1, pp. 1-6, 2013.

[18] G. B. Cline and J. M. Luiz, "Information technology systems in public sector health facilities in developing countries: the case of South Africa," BMC medical informatics and decision making, vol. 13, no. 1, pp. 1-12, 2013.

[19] H. Lærum, T. H. Karlsen, and A. Faxvaag, "Use of and attitudes to a hospital information system by medical secretaries, nurses and physicians deprived of the paper-based medical record: a case report," BMC medical informatics and decision making, vol. 4, no. 1, pp. 1-10, 2004.

[20] Y. Qin et al., "The effect of nursing participation in the design of a critical care information system: a case study in a Chinese hospital," BMC medical informatics and decision making, vol. 17, no. 1, pp. 1-12, 2017.

[21] M. Belay, A. Desta, S. Smithson, and M. Meshesha, "Investigate knowledge management technology implementation for supporting decision making in Ethiopian health sectors," BMC Medical Informatics and Decision Making, vol. 21, no. 1, pp. 1-10, 2021.

[22] !!! INVALID CITATION !!! [19-21].

[23] V. Venkatesh, S. A. Brown, and H. Bala, "Bridging the qualitative-quantitative divide: Guidelines for conducting mixed methods research in information systems," MIS quarterly, pp. 21-54, 2013.

[24] S. Sarbadhikari and S. N. Sarbadhikari, "The global experience of digital health interventions in COVID-19 management," Indian journal of public health, vol. 64, no. 6, p. 117, 2020.

[25] J. Poulos, L. Zhu, and A. D. Shah, "Data gaps in electronic health record (EHR) systems: An audit of problem list completeness during the COVID-19 pandemic," International Journal of medical informatics, vol. 150, p. 104452, 2021.

[26] D. R. Cheng, A. Coote, and M. South, "A digital approach in the rapid response to COVID-19-experience of a pediatric institution," International Journal of Medical Informatics, vol. 149, p. 104407, 2021.

[27] W. He, Z. J. Zhang, and W. Li, "Information technology solutions, challenges, and suggestions for tackling the COVID19 pandemic," International journal of information management, vol. 57, p. 102287, 2021.

[28] M. L. Takemoto et al., "Maternal mortality and COVID-19," The Journal of Maternal-Fetal \& Neonatal Medicine, pp. 1-7, 2020. 
[29] B. Kotlar, E. Gerson, S. Petrillo, A. Langer, and H. Tiemeier, "The impact of the COVID-19 pandemic on maternal and perinatal health: a scoping review," Reproductive Health, vol. 18, no. 1, pp. 1-39, 2021.

[30] A. Milenkovic, D. Jankovic, and P. Rajkovic, "Extensions and adaptations of existing medical information system in order to reduce social contacts during COVID-19 pandemic," International Journal of medical informatics, vol. 141, p.

104224, 2020.

[31] R. Bashshur, C. R. Doarn, J. M. Frenk, J. C. Kvedar, and J. O. Woolliscroft, "Telemedicine and the COVID-19 pandemic, lessons for the future," ed: Mary Ann Liebert, Inc., publishers 140 Huguenot Street, 3rd Floor New ..., 2020.

\section{Figures}

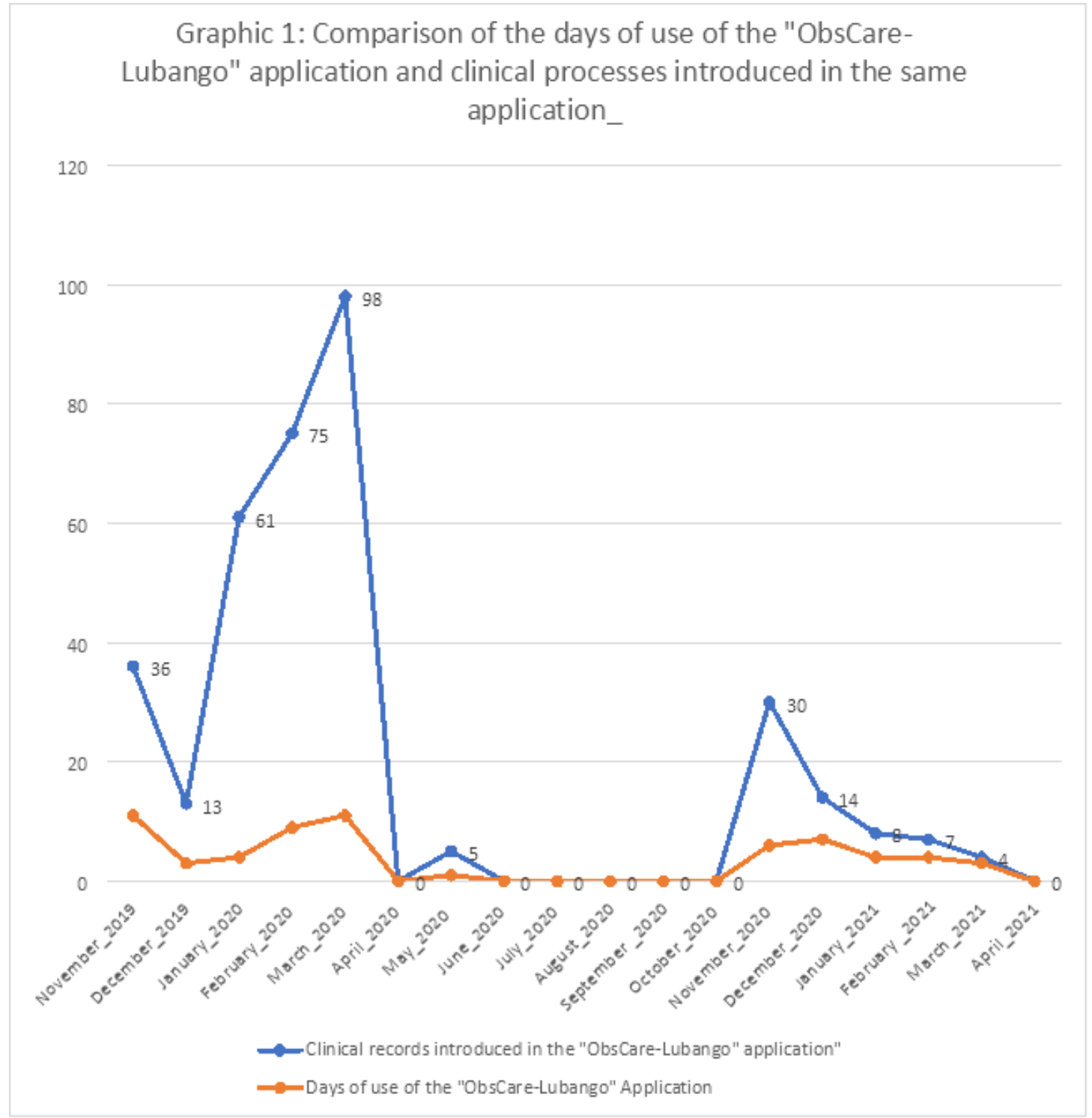

Figure 1

Comparison of the days of use of the "ObsCare-Lubango" application and clinical processes introduced in the same application. Source: Hospital Information System and ObsCare-Lubango Application data April 2021 